\title{
Sexualities and society: a reader
}

J. Weeks, J. Holland and M. Waites (Eds.); Polity Press, Cambridge, 2002, ISBN: 0-7456-2248-

8 (Hbk) £55/ISBN: 0-7456-2249-6 (Pbk) £14.99

Sexualities and Society: A Reader is a most welcome addition to a growing body of scholarship designed specifically for classroom use in the teaching of sexuality studies. While all 24 essays reprinted here have appeared elsewhere, the volume nevertheless remains valuable as it draws together significant work chiefly from a sociological perspective - the majority of contributors, in fact, work in sociology departments, with a smattering from politics, law, history, education, and women's and gender studies. Particular topics, such as queer theory, may be under-represented, but this collection unquestionably fills an important niche in the textbook market.

The introduction is entirely lucid and focused, and gives a clear rationale for the selection of particular materials and areas covered, and indicates, with impressive succinctness, how the field of sexuality studies has evolved over the last few decades. The central objectives of this collection are, as the editors put it, 'to demonstrate how an understanding of sexuality helps us to have a clearer understanding of the development of contemporary societies, conceived in global perspective,' ( $p .1$ ) and 'to introduce a selection of contemporary ideas and perspectives which facilitate the understanding of sexualities.' ( $p .1-2$ ) Thus, the topics are wide ranging and the selections - or 'edited excerpts' - represent both the empirical and theoretical dimensions of the field. Slightly irritating is the way in which we are indeed offered only 'selections,' as the reader's pages are dotted throughout with ellipses sandwiched between brackets ('[...]') to indicate where material has been cut - and this symbol occurs dozens of times on practically each page. This device is no doubt in response to strict space constraints imposed by the publisher, but, as a result, the flow of the arguments presented sometimes feels quite choppy. Students will hopefully be encouraged by these well-chosen excerpts to track down each piece in its original form, and thereby recuperate the nuance and detail - in fact, this is likely the editors' intent as they offer complete bibliographical information.

The reader divides the massive subject of 'sexualities and society' into five thematically coherent parts, each with its own thoughtful mini-introduction: social and historical approaches to sexualities; the gender of sexuality; sexual identities; globalization, power and resistance; and, sexual values and life experiments. The names of most of these (mainly UK) contributors are familiar as they include such leading and influential figures as Dennis Altman, Henning Bech, R.W. Connell, Stevi Jackson, Lois McNay, Ken Plummer, Lynne Segal, William Simon, and Randolph Trumbach, to name just a few. In the first section on the 'social and historical approaches to sexualities,' the editors argue forcefully for the importance of a 
'historical perspective,' because it enables us to track the shifts in the way sexuality has been conceptualized and constructed in different societies, contexts and temporalities (modern and postmodern). Here, the editors introduce three main questions for students to consider as they move through the remaining sections, namely: 'How is sexuality socially organized? How do we research sexuality? And how do the ways in which sexuality is narrated and represented shape the ways in which it is experienced?' (p. 11). This section continues the discussion, first raised in the volume's introduction, on the history of sexual knowledge, a field that has been tremendously enriched by the groundbreaking scholarship of Jeffrey Weeks. A somewhat surprising contribution in this section is William Simon's 'The Postmodernization of Sex'; the editors remind us, though, that an insight often attributed to Michel Foucault - that 'society shapes sexuality' was first articulated by social scientists John Gagnon and Simon a few years earlier. While the second and third sections (on 'the gender of sexuality' and 'sexual identities') may be all too predictable to specialists in gender theory, these passages, nevertheless, cover all major points essential for newcomers - the target audience - and, again, with striking concision. The latter two sections ('globalization, power and resistance' and 'sexual values and life experiments'), may hold interest even for those of us who rarely dip into the 'reader format,' since the combination of materials is freshly conceived, and the thematic structuring is timely. The introduction to the final section, for example, observes how 'sexuality has itself always been an arena of moral and cultural conflict,' ( $p$. 24l) and points out that, increasingly, sexuality is becoming a 'central and explicitly debated issue in mainstream cultural conflicts and political debates over values and citizenship.' (p. 241) These sections should convince students of the importance and relevance of sexuality studies.

My only disappointment in this project overall is its cursory treatment of queer theory, because the lack of coverage here works to shortchange students who may wish to pursue further an area that has also played a major role in the shaping of this field. Even so, the politics of inclusion and exclusion inevitably linger around a venture of this sort, and Sexualities and Society generally avoids most of the pitfalls, promising its readers instead a thorough and thoroughly responsible introduction to current trends in sexuality studies, especially in its sociological dimensions.

doi: $10.1057 /$ palgrave.fr. 9400147

Laura Doan 